Published in the Proceedings of the Hawaii International Conference on System Sciences, January 2004

\title{
Competitive Bidding Behavior in Uniform-Price Auction Markets
}

\author{
Peter Cramton \\ University of Maryland \\ cramton@umd.edu
}

\begin{abstract}
Profit-maximizing bidding in uniform price auction markets involves bidding above marginal cost. It therefore is not surprising that such behavior is observed in electricity markets. This incentive to bid above marginal cost is not the result of coordinated action among the bidders. Rather, each bidder is independently selecting its bid to maximize profits based on its estimate of the residual demand curve it faces. The supplier bids a price for its energy capacity to optimize its marginal tradeoff between higher prices and lower quantities. Price response from either demand or other suppliers prevents the supplier from raising its bid too much. Profit maximizing bidding should be expected and encouraged by regulators. It is precisely this profit maximizing behavior that guides the market toward long-run efficient outcomes.
\end{abstract}

\section{Introduction}

The cornerstone of competitive market behavior is that each supplier seeks to maximize profits. It is this profit maximizing behavior by individual market participants that steers Adam Smith's “invisible hand," leading to efficient outcomes for the market as a whole. The benefits of independent profit maximizing behavior occur in perfectly competitive markets, but such benefits also arise in a wide range of real-life markets, including competitive wholesale electricity markets.

In reaction to the crisis in the California electricity markets in 2000-2001, much attention has been focused in the economic literature on whether suppliers in the California markets have violated competitive norms by bidding resources at prices in excess of marginal costs [2, $5,10]$. As a matter of economic theory and sound market design for wholesale electricity bid-based auction markets, there is and should be no competitive norm stipulating that suppliers' bids should equal marginal costs. The lack of marginal cost bidding is not evidence of anticompetitive or manipulative behavior by market participants, nor is it evidence even that competition is failing or that markets are broken. In any real-world market in which suppliers are not forced by conditions or rules to be price takers, bidding above marginal cost is consistent with and, indeed, is impelled by independent, non-collusive, profit maximizing behavior. Bidding above marginal cost should be viewed as an inevitable and desirable response of independent, profit maximizing decisions in real-world markets where the ideal conditions of a perfectly competitive market do not prevail.

Bidding behavior in electricity markets should not, therefore, be assessed against a norm of marginal cost bidding, which applies only in the theoretical extreme of perfect competition. While some may use this extreme point as a convenient benchmark, it is not the norm for rational, profit maximizing behavior by independent competitors. In real bid-based electricity markets operating under a range of supply and demand conditions, individual suppliers should be bidding to maximize their profits, which, as this paper explains, will inevitably involve bidding above marginal cost. Bidding above marginal costs is and should be the competitive norm in uniformprice electricity auction markets.

Bidding above marginal cost is an inevitable consequence of profit maximizing decisions whenever at least one supplier has some unhedged capacity. In these circumstances, which characterize most bid-based markets, including electricity markets, each supplier expects to maximize its profits by offering its unhedged output at prices above marginal cost. Bidding above marginal cost to maximize profits should characterize all suppliers in all competitive, bid-based electricity markets. In particular, rational bidding above marginal cost does not entail or require: (1) the presence of one or more large bidders, (2) extreme supply scarcity, (3) demand that is unresponsive to price, or (4) collusion or other bid coordination among suppliers. Rather, any supplier with unhedged capacity maximizes profits by offering supply at bid prices higher than marginal cost.

A main theme of this paper is to demonstrate that marginal cost bidding is an abstract, ideal characteristic of perfectly competitive markets, but it should not be considered the norm for competitive wholesale electricity markets. A corollary is that bidding above marginal cost in competitive wholesale electricity markets is consistent with non-manipulative, non-collusive, profit maximizing behavior. Bidding marginal cost maximizes profits only for capacity that is already sold in forward markets. Suppliers of all unhedged capacity have an incentive to bid above marginal cost. It is for this reason that one 
commonly observes pricing above marginal cost in most real markets. Hotels, parking, rental cars, airlines, and electricity are all examples of markets where supply is rationally offered at prices above marginal cost.

A supplier that bids above marginal cost to maximize profits does not have unlimited power to charge whatever it wants. The supplier's bids are limited by the competitive response of other suppliers as well as any response by demand. As the supplier raises its price it runs an increasing risk that either another supplier will step in to serve demand or that buyers will curtail demand. At the same time, the response by demand and other suppliers is not unbounded. Demand may have a limited ability to curtail quantity in response to higher prices and other suppliers may be limited in their ability to step in to meet demand. These limits imply that suppliers are not price takers, but face a fundamental, marginal tradeoff between the quantities they offer to sell and the prices that they would expect to receive.

In auction markets, suppliers develop bid curves, which normally have higher prices bid for higher quantities of output offered. A profit-maximizing supplier in developing its bid curve balances the marginal gain from bidding a higher price for a given quantity of output, with the marginal loss from selling a smaller quantity at such higher price. The supplier is limited in the price that it offers by the expectation and reality that as it raises its bid prices, the quantity it is able to sell falls, either because other suppliers fill in additional quantity at lower bids, or demand itself falls in response to the higher price.

In the idealized extreme of a perfectly competitive market, suppliers would have absolutely no decision to make at all with respect to their bid curve. Each and every supplier is presumed to be a price taker, which implies that profits are maximized by bidding marginal cost. In realworld competitive markets, in which suppliers come to each market with some unhedged capacity, suppliers are not price takers and should not be expected to act like one. Suppliers will choose their bid curves so as to maximize their profits, which will entail making independent decisions trading off marginal gains from a higher bid curve against marginal losses from foregone output. This is the essential profit maximizing decision expected of each supplier, acting independently, in bid-based electricity markets. This profit maximizing behavior will, as this paper demonstrates, result in bid curves above marginal cost, some supply being unsold or "withheld," and clearing prices in excess of prices hypothesized in a theoretical perfectly competitive market.

Profit maximizing bidding is the norm we expect of suppliers in bid-based electricity markets. Following this norm does not mean that market clearing prices will necessarily be just and reasonable under all market structures and under all supply and demand conditions. Nor does it mean that regulators should eschew market rules that will decrease pressures on clearing prices under certain conditions. The key is that market rules need to be designed around the normative expectation that suppliers in bid-based auction markets will not submit bid curves at their expected marginal costs, but, instead, will make profit maximizing decisions that trade off marginal gains from raising bids against marginal losses in foregone output.

\section{Preliminaries}

Terminology matters. To avoid confusion, it will be useful to define a few terms.

Marginal cost is the supplier's opportunity cost of producing an additional unit of output. It includes the supplier's marginal production cost, but also includes opportunity costs, such as the sale into a higher priced market, and incremental costs from constraints, such as those arising from emission limits or capacity limits. When an electric generator is not operating, its pertinent marginal costs include costs associated with start-up and no-load operations. The supplier, all else being equal, is indifferent to selling an additional unit at marginal cost or not. Electric generators' marginal costs typically increase with output, and increase steeply as full capacity is reached. This is the bidder's marginal cost curve-its marginal cost at each possible quantity.

Opportunity costs arise in interrelated markets. A hydroelectric resource fed from a limited pool of water is a good example of opportunity costs, since generating power today implies less available generating capacity tomorrow. Therefore, even though today's price is above the hydro generator's variable cost (zero), the generator has an incentive to bid at least its opportunity cost based on its prediction of future prices.

Opportunity costs are not confined to hydro generation. Gas-fired generation, particularly in California, is subject to NOx constraints. In some locations, these represent hard constraints: a plant may have a fixed amount of $\mathrm{NOx}$ permits per year, and once those are used, the plant cannot be run further. Similarly, even in the presence of tradeable NOx permits, producing today has an added cost equal to the permit price.

Perhaps the biggest source of opportunity cost in power markets arises from the sequential clearing of related markets. Selling in the day-ahead market forecloses the option of selling in the real-time market; selling in the dayahead energy market precludes selling in the ancillary services market; and selling in the California market precludes selling in a neighboring market. The bids of a 
profit maximizing generator will reflect these opportunity costs.

In a bid-based auction market, a supplier submits a bid price for each quantity indicating its offer to supply. This is called the bidder's as-bid supply curve, or simply its supply curve.

In a uniform-price auction, the auctioneer takes the asbid supply curves of each bidder and adds them together in the quantity dimension to form the aggregate supply curve. A common alternative is for bidders to express supply as a piecewise linear function. Each bidder's as-bid supply curve is required to be non-decreasing in quantity as prices rise-a bidder cannot reduce its quantity in response to higher prices.

Similarly, the auctioneer aggregates the price-quantity bids of each demand-side bidder to form the aggregate demand curve. The auctioneer then determines the marketclearing price as the price where the aggregate supply and demand curves intersect (the point $\left(q_{0}, p_{0}\right)$ in the figure below). All supply offers below the clearing price are winning bids and are asked to supply the quantity bid, with each supplier paid the clearing price $p_{0}$; all demanders receive the quantity they bid above $p_{0}$ and pay the clearing price $p_{0}$.

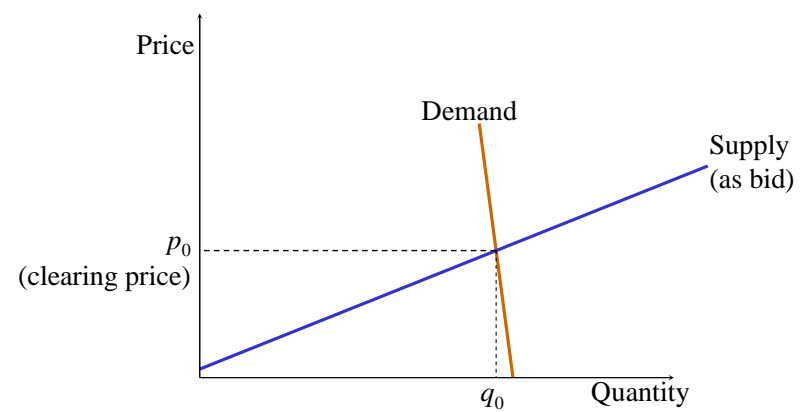

In the figure above as well as subsequent figures, demand and supply are drawn as straight lines. This is for convenience only. In practice, the curves are nonlinear and discontinuous. More importantly, the figures as drawn do not reflect the inherent uncertainty in both demand and supply. A supplier knows its own supply bid, but it must estimate its own marginal cost curve, the aggregate demand, and the supply curves of the other bidders based on incomplete data. This graphical representation of bidding behavior simplifies the supplier's actual profit maximizing decision. One can interpret the figures as one possible realization. In actuality, each supplier decides on its bid-curve based on its appraisal of all possibilities and the associated likelihoods of these possibilities. Each point on its supply curve is chosen to maximize profits for instances in which the bid is on the margin.

The importance of uncertainty is highlighted by the fact that the supplier submits a whole supply curve. If there was no uncertainty, the supplier could instead submit just a single point: "Firm $i$ will supply $q_{i}$ at the clearing price of $p_{0}$." Rather, the supplier submits a continuum of pricequantity pairs, expressing its profit-maximizing quantity choice for the domain of all prices that can occur under all possibilities.

In making its decision on the quantity to supply at all relevant prices, the supplier needs to estimate both demand and the supply provided by others at all possible prices. These estimates give the supplier an understanding of how much of the aggregate demand will remain, once the supply of the other bidders has been netted out. The supplier's estimate takes into account not only how responsive demand is to price, but also how responsive the supply of the other bidders is to price. From this analysis, the supplier calculates a critical input to its bidding decision-its estimate of the residual demand curve. Formally, the residual demand curve is constructed by taking the aggregate demand and subtracting the supply of the other bidders, as shown below.

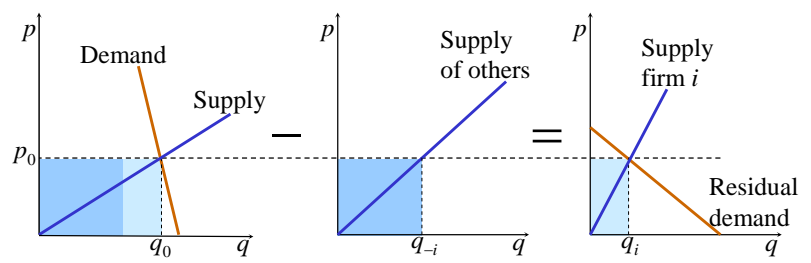

Notice that even if the demand curve is nearly vertical (inelastic), the residual demand curve typically is much more responsive to price (elastic), since it includes the response to price of all the other suppliers. Throughout, firm $i$ will represent a typical supplier, with as-bid supply $S_{i}$ and marginal cost $M C_{i}$. Let $-i$ denote the set of all suppliers other than $i$, and let $S_{-i}$ and $M C_{-i}$ denote the aggregate supply and marginal cost of the bidders other than $i$. The residual demand curve for supplier $i$ is denoted $D_{i}$. The quantity $q_{i}$ supplied by bidder $\mathrm{i}$ is determined from the intersection of its supply $S_{i}$ and residual demand $D_{i}$, as shown below.

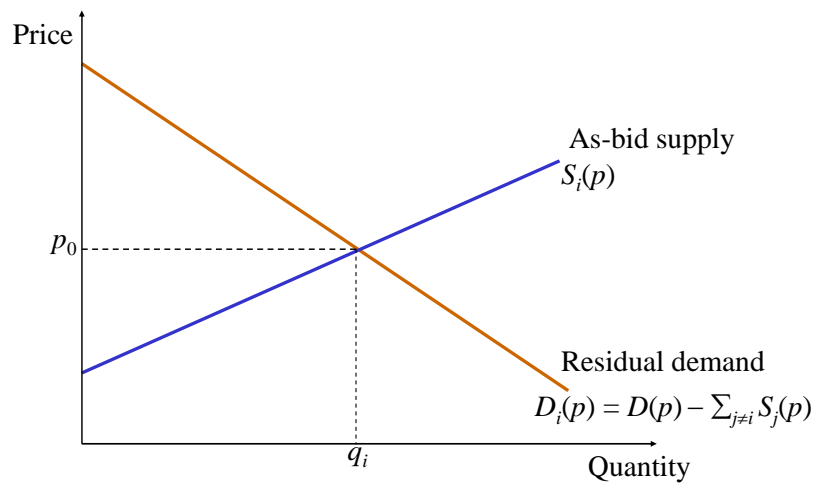

One common economic model that is applied in analyzing electricity markets is perfect competition. Perfect competition assumes that there are an infinite 
number of sellers and buyers, so that no market participant can affect price. As a consequence, all buyers and sellers are price takers: each seller offers to supply the market with a quantity of the product at a price just equal to its marginal cost of production, and each buyer offers to purchase a quantity of the product at a price equal to the marginal value it places on the product. Under perfect competition, no bidder - on either the supply side or the demand side-is able to affect the market-clearing price through its bids.

The model of perfect competition is simple to apply to electricity markets. The assumption that no supplier is able to impact the market-clearing price implies that each bidder faces a horizontal residual demand curve, as shown below. The market will accept any quantity from the bidder at the clearing price $p_{0}$. As a result, no bidder has an incentive to bid above its marginal cost curve. The profitmaximizing bidder simply bids its marginal cost curve, $S_{i}(p)=M C_{i}(p)$. Increasing the bid above marginal cost would eliminate some profitable sales without any corresponding gain from a higher price.

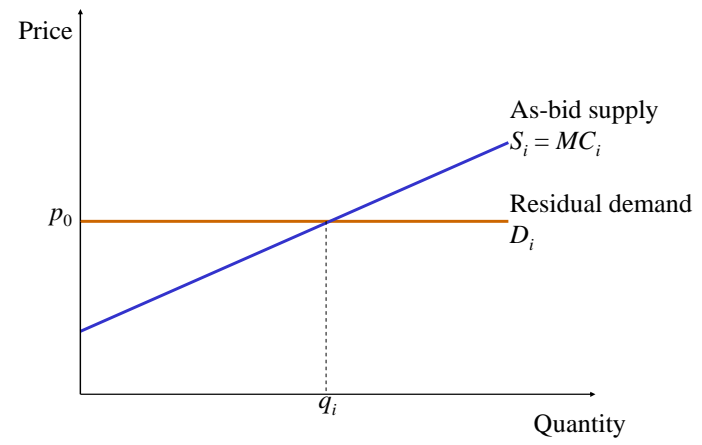

Marginal cost bidding has the further benefit of efficient dispatch. Energy is supplied by the least-cost units. As a result of its simplicity and desirable efficiency properties, marginal cost bidding often is used as a benchmark to compare with actual market performance [2, 4]. It even is sometimes asserted that suppliers should bid marginal cost in a competitive electricity market. This prescription for behavior, however, is only appropriate in the extreme and unrealistic case of perfect competition as we will see next. Only under perfect competition-a setting that requires that no firm supply more than one MWh of energy in any hour-is marginal cost bidding consistent with profit maximizing behavior. Such an assumption is inconsistent with the practical realities of electricity generation.

Economists define market power as the ability of a supplier to affect the market-clearing price. Under economic theory, the only markets in which suppliers do not have the ability to affect the market-clearing price are perfectly competitive markets. Each supplier in a perfectly competitive market is hypothesized to be a price taker-its bidding decisions would have no affect on the market clearing price. In real-world competitive markets, economic theory recognizes that a supplier faces a downward-sloping residual demand and, therefore, its bidding decisions have the potential to affect the market clearing price. Thus, in economic terms, the exercise of market power amounts to nothing more than a supplier's ability to construct a profit-maximizing as-bid supply curve that is above its marginal cost curve. In the context of electricity markets, such behavior can be called economic withholding, but such a label does not make the conduct anticompetitive, manipulative, or otherwise impermissible. Physical withholding -failing to submit a bid for all available capacity when the price is above its marginal cost-is another variant of exercising market power, but such conduct also is not anticompetitive, manipulative, or otherwise impermissible.

The exercise of market power does not imply that a supplier unilaterally moves the market price above a competitive level. Rather, the exercise of market power reflects an individual supplier's construction of a bid curve based on its calculations of profit maximizing bids. The resulting market clearing price reflects the demand curve and the as-bid supply curves submitted by all suppliers acting independently in a profit maximizing manner. I will use the economists' definition of market power throughout. Under this definition, the exercise of market power by itself is not anticompetitive or manipulative.

\section{Independent profit-maximizing behavior is the basis for market prices}

A cornerstone of markets is independent profitmaximizing behavior. It is precisely this behavior that steers Adam Smith's “invisible hand” to produce efficient market outcomes: "It is not from the benevolence of the butcher, the brewer, or the baker that we expect our dinner, but from their regard to their own interest.” [11] As in any market, competitive suppliers in electricity markets are motivated by profits. Independent profit-maximizing behavior should not only be expected but encouraged by regulators, provided the behavior is consistent with the market rules. In restructured power markets, the role of market-based rates is to allow suppliers to pursue profit maximization in submitting bids or negotiating prices in a bilateral transaction.

The role of regulators is to design and monitor a set of market rules that relies on the independent profitmaximizing behavior of the market participants to achieve the objective of providing consumers with low-cost, reliable power. In certain contexts, resulting prices may be deemed unjust and unreasonable by regulators and, accordingly, market rules may be modified so as to 
influence future market clearing prices produced by individual profit maximizing bidding decisions.

\section{Competitive bidding in real markets}

Since the time of Adam Smith, economists have developed several economic models with which to analyze the behavior of buyers and sellers in markets. The most tractable economic models relate to the polar extremes of perfect competition and monopoly. Under perfect competition, each firm is a price taker-its actions cannot impact the market price, and so its decisions take price to be fixed. Under monopoly, the firm has no competitors, and so in developing a strategy the monopolist need not factor in the likely behavior of its competitors. Almost all actual markets, and certainly all power markets, are somewhere between these two extremes. In bid-based wholesale power markets, each firm has the potential to affect the market clearing price through its independent price and quantity bidding decisions, but the best profit maximizing actions by one firm will depend on its expectations of the profit maximizing actions chosen by its competitors. This is the realm of imperfect competition, where strategy and uncertainty play important roles.

The use of the model of perfect competition stems from its simplicity, not its universal validity or applicability to real world markets. Economists understand that perfect competition is a convenient polar extreme, which although rarely observed in practice, does provide a useful approximation of outcomes in some markets. As a consequence, the model of perfect competition can provide general guidance for regulators and other architects of market design, but it does not provide a useful norm of competitive behavior.

Real markets are not perfectly competitive. Even in highly competitive markets with no entry barriers, firms typically find that their individual behavior can affect the market price. Certainly for current electricity marketscharacterized in almost all geographic locations by large capacity investments and moderate to high concentration of ownership, it would be unreasonable to suppose that the ideal of perfect competition should prevail. In each of the regional electricity markets, the largest suppliers operate a substantial share of the generation capacity, but each supplier also faces competition from numerous other suppliers. In markets like this, especially in the presence of transmission constraints, perfect competition is likely a poor model — either normative or descriptive — of pricing behavior.

Yet many observers, including the California ISO, have presented the lack of marginal cost bidding as evidence of anticompetitive behavior or an abuse of market power by firms in California' spot electricity market [10]. Bidding above marginal cost is not evidence of bad behavior; rather it is evidence of profit maximizing behavior. Only in the theoretical extreme point of perfect competition is marginal cost bidding consistent with profit maximization. Bidding above marginal cost is an inevitable consequence of profit maximization whenever there is a positive probability that a supplier's bid may impact the market clearing price. In this plausible case, applicable to most actual markets, individual profit-maximizing behavior results in submitting bids above marginal cost.

The theory of bidding in uniform-price auctions under conditions of imperfect competition has been developed extensively in the economic literature [1, 6]. In this theory, each supplier submits a bid function to maximize its profits given its marginal cost curve, its expectations about market demand, and its expectations of the supply curves of the other bidders. The theory has several important implications: (1) so long as there is some probability that the supplier's bid may affect the clearing price, the profitmaximizing bid curve exceeds its marginal cost curve; (2) the spread between its optimal bid and marginal cost increases with the quantity that the bidder is supplying; (3) the spread between its optimal bid and marginal cost increases the less responsive the supply of the other bidders is to price; (4) the greater incentive for larger bidders to inflate bids above marginal cost implies a shortrun inefficiency-too little of the market is served by the largest bidders; and (5) forward contracts have the effect of mitigating incentives to bid above marginal cost. I now provide a simple demonstration of each of these implications as well as some intuition.

\section{Profit-maximizing suppliers bid above marginal cost}

Each bidder in a uniform-price auction faces a fundamental tradeoff between price and quantity. By offering to supply at a lower price, the bidder increases the likelihood that it will supply a larger quantity; whereas, by offering to supply at a higher price, the bidder increases the likelihood that it will supply a smaller quantity but at a higher price. A rational bidder optimizes this tradeoff to maximize profits. This involves setting its bid at each quantity at the point where the marginal gain from bidding a little bit higher (a higher price on the quantity sold) exactly balances the marginal loss (failure to get the spread between the bid and marginal cost on the expected available quantity that will go unsold as a result of the higher bid).

As a simple example, consider the pricing decision of a firm operating a 1,000 MW unit with a marginal cost of \$49/MWh at capacity. Rational behavior typically will lead this firm to bid the last MW of capacity at the price cap of, say, \$250/MWh. To see this, consider the decision of the firm to raise its bid on the last MW from $\$ 249$ to $\$ 250$. The marginal gain from such a bid is 1,000 
multiplied by the probability that the last MW sells at \$250; whereas, the marginal loss is equal to the foregone profit on the last MW (\$249 - 49) multiplied by the probability that the market clearing price is $\$ 249$ (and not \$250). Bidding the price cap is the best strategy for the firm, provided the marginal gain exceeds the marginal loss. In this example, the marginal gain will exceed the marginal loss, so long as the probability of a \$249 market clearing price is less than 5 times the probability of a $\$ 250$ market clearing price. Hence, the $\$ 250$ bid is optimal, unless the bidder believes that raising its bid by the last $\$ 1$ will reduce its chance of selling the last MW by more than a factor of 5 . The intuition for this result is straightforward: by raising its bid by $\$ 1$, the bidder achieves the $\$ 1$ higher price on all 1,000 MWs when the bid sets the price; whereas the $\$ 200$ loss (\$249 - 49) only occurs on the last MW when the increase prevents the MW from being sold.

This calculation does not imply that the "sky's the limit" with respect to the firm's price and quantity bids. Profit-maximizing bidders face a real danger from bidding too high. They run the risk that their capacity will go unsold as a result of offering a price that is too highsome other bidder may step in front of them in the merit order, or the quantity demanded may fall as a result of offering a price that is too high.

The incentive to bid above marginal cost is seen in the figure below. Imperfect competition implies that the bidder's residual demand curve is downward sloping. By raising its bid above marginal cost, it achieves a high price on all of its quantity. The marginal gain is represented by the green rectangle. The marginal loss (the loss of providing some quantity at marginal cost) is given by the red triangle. Whenever the residual demand curve is downward sloping, the marginal gain will exceed the loss for small enough upward shifts in the as-bid supply curve beyond the marginal cost curve.

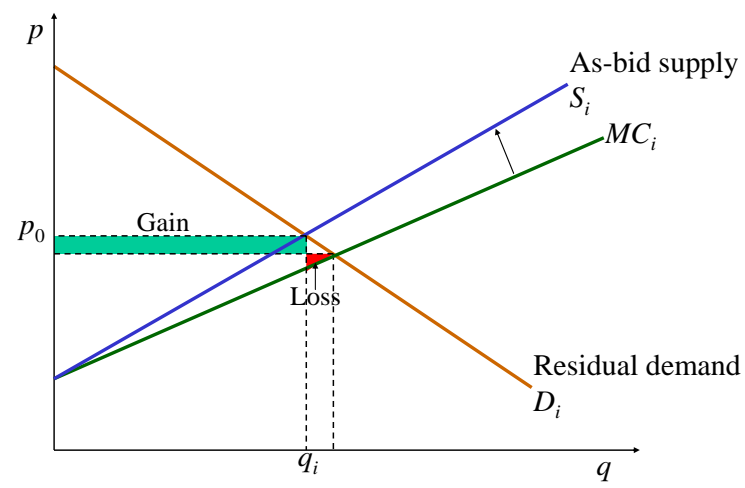

To maximize profits, the bidder continues to increase its bid curve above its marginal cost curve until the equilibrium point is reached. At the equilibrium point, a slight increase in the bid leads to a marginal gain (a higher price on the quantity sold) that exactly balances the marginal loss (the profit lost as a result of the reduced quantity). This is seen in the figure below, in which the marginal gain is given by the green rectangle and the marginal loss is given by the red area. Offering $q_{i}$ at the clearing price $p_{0}$ just balances the marginal gain and loss.

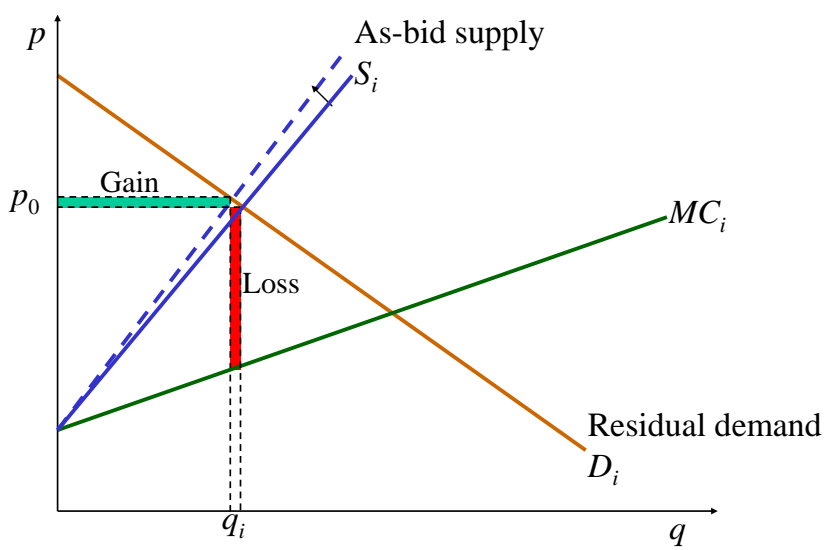

This incentive to bid above marginal cost is not the result of coordinated action among the bidders. Rather, each bidder is independently selecting its bid to maximize profits based on its estimate of the residual demand curve it faces. To see this, suppose that there are eleven suppliers in the market, each with the same marginal cost curve. Consider the bidding incentives of one firm (firm $i$ ) when the other ten are all bidding marginal cost. This is shown in the figure below. Since each of the ten other firms is bidding marginal cost, the others would supply the entire market demand at a price of $p_{-i}$. Firm $i$ then is facing the residual demand $D_{i}$, which begins at the price $p_{-i}$. Since the residual demand is downward sloping, firm $i$ optimally bids $S_{i}$, which is above marginal cost. As a result, firm $i$ supplies $q_{i}$, pushing the clearing price down to $p_{0}$.

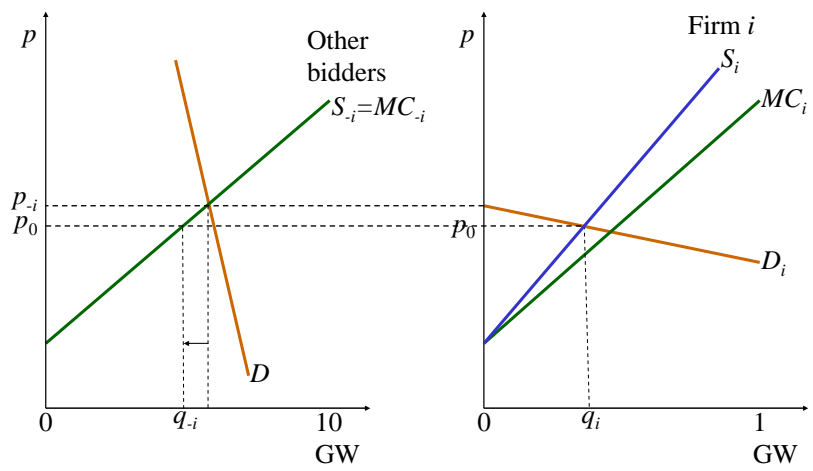

The behavior described above represents one firm's profit-maximizing response to all the other firms bidding marginal cost. However, this is not an equilibrium, since none of the other firms have an incentive to bid marginal cost. Like firm $i$, each of the others has an incentive to bid above marginal cost. The equilibrium bidding behavior is depicted in the figure below, where each of the similarly 
situated firms is doing exactly what firm $\mathrm{i}$ is doing: bidding above marginal cost to optimize the expected price-quantity tradeoff. In equilibrium, firm i's bid above marginal cost is such that the marginal gain from the higher price is exactly offset by the marginal loss of some profitable quantity. This calculation is made assuming a residual demand curve that correctly anticipates that each of the other bidders is also bidding to maximize its own profits and hence bidding in a similar way, as shown below in the supply curve $S_{-i}$ of the other bidders.
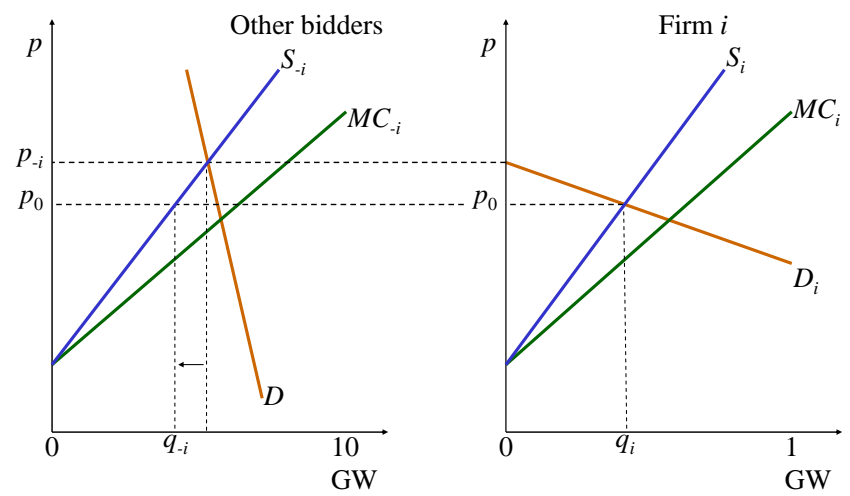

In practice, determination of the optimal supply function is complicated by the firm's uncertainty about its residual demand curve. The firm faces uncertainty about both the aggregate demand and the supply functions adopted by its competitors. As a result, the firm selects each point on its supply function to optimize the tradeoff between price and quantity given the distribution of residual demand curves the firm faces. The introduction of uncertainty complicates the firm's decision problem, but does not alter the fundamental tradeoffs that are presented in the figures.

\section{Physical withholding is analogous to bidding above marginal cost}

Discussions relating to power markets frequently invoke the concept of supplier "withholding" behavior.

Economic withholding is identical to bidding above marginal cost: a supplier decides to produce less than is economically feasible at a given price level, because the higher price level associated with the lower output maximizes the supplier's profits. Here, economic feasibility is based on the supplier's marginal cost, including any opportunity costs. These opportunity costs are especially important when the product is sold in a sequence of related markets, as is the case in power markets.

Physical withholding, in which firms fail to bid in their economically feasible capacity above a certain amount, is often described as a separate strategy from economic withholding. However, the two are closely related. Both result in output that is less than the quantity that could be economically produced at the prevailing price, as shown in the figure below.
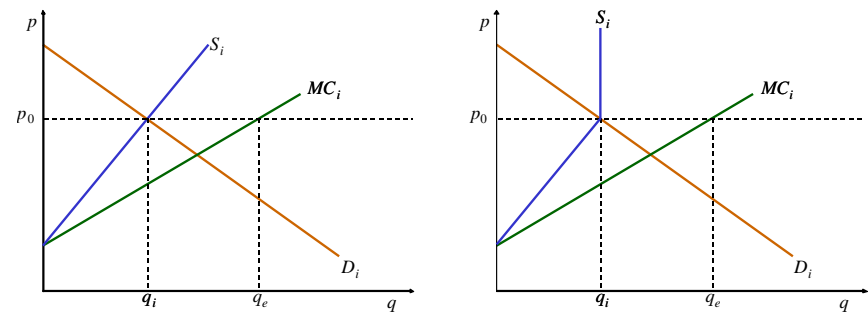

The difference between economic and physical withholding arises from the uncertainty in the residual demand curve the supplier faces. With physical withholding the supplier is more apt to regret its supply bid in the event that its residual demand is higher than expected. Why then would a supplier choose to physically withhold capacity? One reason has to do with nonconvexities in the supplier's cost function that it is unable to express in its bid. For example, as a result of start-up and no-load costs, the supplier may expect to be better off physically withholding a unit, rather than including the unit in its supply bid. Start-up and no-load costs may not be justified for a unit that is expected to run only a short period of time.

\section{The incentive to bid above marginal cost increases with quantity}

In the figure above, the spread between the as-bid supply and the bidder's marginal cost curve increases with quantity. This is a characteristic of a profit-maximizing supply function. The reason is simple. The marginal gain from an increase in the bid is proportional to the quantity sold. As more quantity is sold, the buyer has a greater incentive to increase the as-bid supply curve above the marginal cost curve. Likewise, as the quantity sold falls to zero, the spread between the optimal supply bid and the firm's marginal cost goes to zero. There is no incentive to increase the price if doing so results in no quantity sold.

\section{The equilibrium price falls as competition increases}

The fact that a bidder's incentive to bid above marginal cost increases with its quantity has an immediate implication: the equilibrium market clearing price falls as the market becomes less concentrated. In a less concentrated market, bidders are smaller and hence have a reduced incentive to bid above marginal cost. In terms of the residual demand curve, a smaller bidder faces a flatter residual demand curve. Other competitors are better able to cover the capacity of a smaller bidder withholding some of its quantity. Hence, the profit-maximizing bidders in a less concentrated market bid a smaller margin above marginal cost, resulting in a lower clearing price. 


\section{Demand and supply response mitigates incentives to bid above marginal cost}

A primary determinant of how much to bid above marginal cost is the responsiveness of the residual demand to changes in price. If the residual demand curve is not too responsive to price as in the figure above, then the optimal bid requires a large margin above marginal cost. If instead the residual demand curve is responsive to price as in the figure below, then the margin above marginal cost is less.

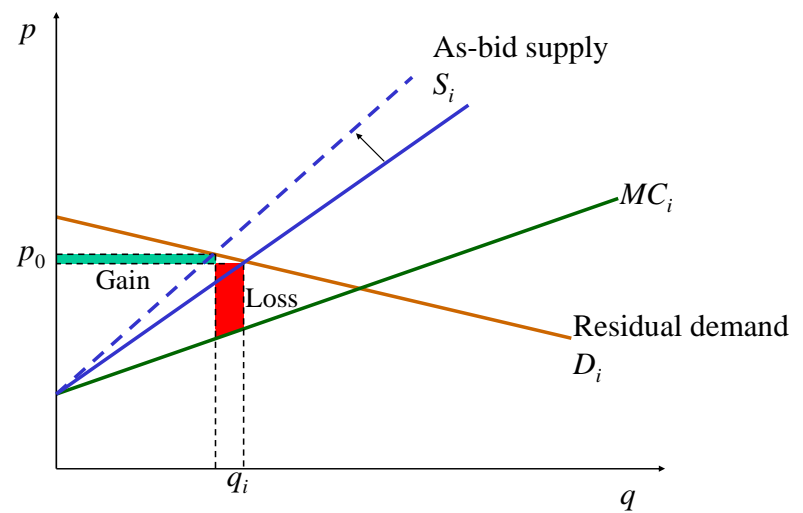

The responsiveness of the residual demand curve comes from either: (1) load reducing demand in response to higher prices, or (2) other suppliers expanding supply in response to higher prices. Current electricity markets have suffered from a lack of demand response. Over time, as demand becomes more price responsive, the incentives for suppliers to submit bids in excess of marginal costs will be reduced. Supply response typically depends on how close the system is to capacity. When there is ample excess capacity, then other suppliers step in when one supplier curtails production - the price impact of the curtailment is minimal. In contrast, when capacity is scarce, then substantially higher prices may be needed to attract sufficient supply to make up for the curtailment of supply by one bidder.

The responsiveness of the residual demand curve also depends on how close the market is to real time. As markets approach real time, participants lose the ability to respond to price changes. For example, units with substantial start-up times or low ramp rates are unable to offer additional energy on short notice. As a result, both supply and demand become steeper-more inelastic - as the market approaches real time. Hence, real time markets tend to be the most vulnerable to the exercise of market power, as defined by economists. As the aggregate demand and supply curves become more inelastic, individual suppliers are faced with increasingly inelastic (steeper) residual demand curves, providing increased incentives for bidding their remaining capacity above marginal costs.

\section{Large bidders serve too little of the market}

Each supplier faces a different residual demand curve. The shape of the residual demand curve depends on the size of the individual supplier. Typically, the residual demand curve will be steeper for a larger supplier and flatter for a smaller supplier. In the figure below, the large bidder has 10 times the capacity of the small bidder. As a result, the large bidder's ability to affect price is much greater: a drop in supply of 5,000 MWh leads to a much larger price impact than a drop of $500 \mathrm{MWh}$. Hence, the residual demand of the large bidder appears about 10 times as steep as the small bidder. (Actually, the slopes may be identical, but the residual demand of the large bidder appears 10 times steeper, since the large bidder has 10 times the generating resources.)
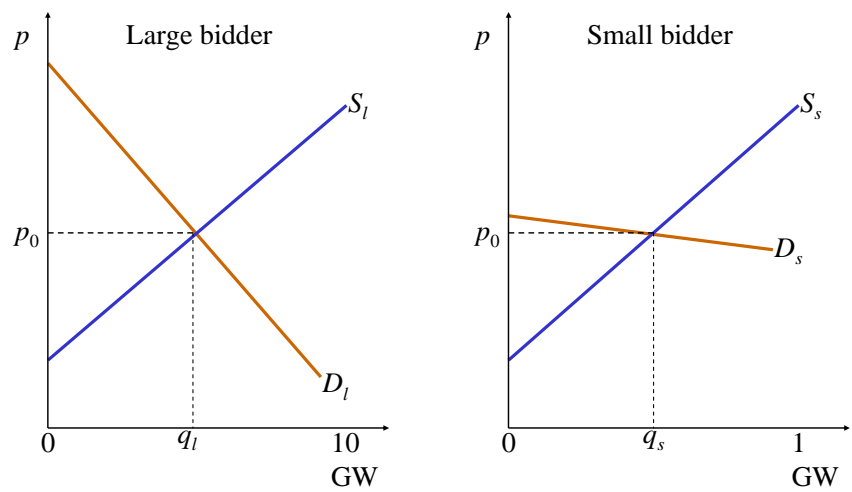

The implication of a steeper residual demand is that the large bidder optimally increases its bid above marginal cost more than the small bidder, as shown below. As a result, at the clearing price p0, the large bidder has a lower marginal cost than the smaller bidder. The large bidder is economically withholding some of its capacity, which enables its smaller rivals to produce more. This result implies the introduction of inefficiency into the dispatch: the smaller rival supplies capacity to the market, even though more efficient capacity from the larger bidder is available and unused at the market clearing price.
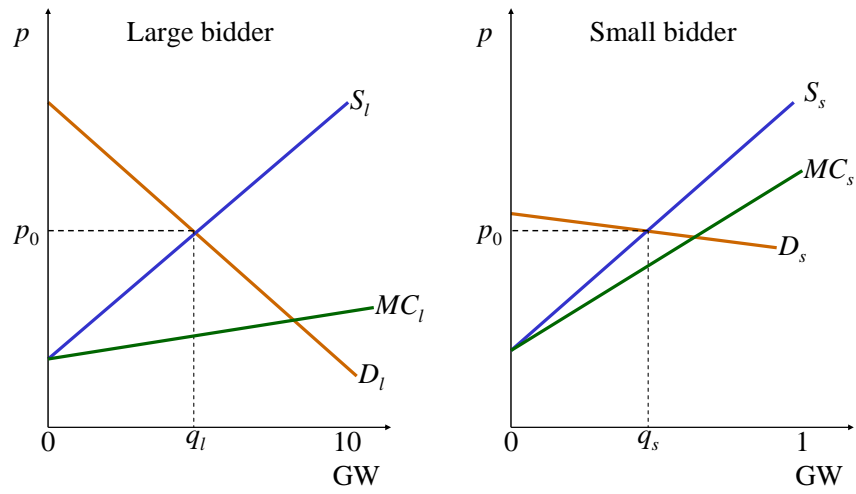

Although the dispatch is inefficient, the impact of the inefficiency is to enable smaller firms to operate relatively more efficiently than larger firms, since the smaller firm is 
using a larger percentage of its available capacity than it would in the absence of withholding by the large bidder. In the long run, this encourages entry and growth of smaller firms and an improved market structure, flattening the residual demand curves for all firms -including the large bidder-and thereby reducing over time the spread between the as-bid supply curve and the marginal cost curve. Profit maximizing behavior in a uniform-price auction corrects problems of market structure absent barriers to entry. Thus, the short-term inefficiencies caused by imperfect competition send the right price signals to induce long-term efficient outcomes.

\section{Forward contracts mitigate incentives to bid above marginal cost}

The analysis above assumes that the bidders do not have any forward contracts going into the market. In practice, forward positions are common, so it is important to examine how incentives change as a result of forward contracts. Indeed, forward contracts play a critical role in mitigating the incentive to bid above marginal cost.

To see this, consider a supplier that has sold $100 \%$ of its generation forward. Such a supplier is fully hedged and has no incentive to bid above marginal cost. The supplier already knows the price it will receive from the terms of the forward contract. The supplier has no interest in distorting the clearing price either upward or downward. Its incentive is to bid its marginal cost, so that it can satisfy the forward contract with its own generation whenever it is the least-cost supplier. If instead the supplier's marginal cost at full capacity is above the clearing price, then the supplier will produce only to the point where its marginal cost is equal to the clearing price, and it will then satisfy the remainder of the forward contract with purchases from the spot market. Marginal cost bidding maximizes profits for a supplier that has sold $100 \%$ of its generation forward.

A firm that sells most, but not all, of its generation forward alters its bidding incentives in a similar way. For example, if a large firm with $10 \mathrm{GW}$ of capacity, sells $80 \%$ of its capacity forward, then its bidding incentives in the spot market are the same as a small bidder with $2 \mathrm{GW}$ of unhedged capacity. The large firm has no incentive to bid above marginal cost on the first $8 \mathrm{GW}$ of capacity; it only begins to bid above its marginal cost on its last $2 \mathrm{GW}$ of capacity. In this way, the supplier satisfies its forward obligation at least cost, and maximizes its profits on its remaining 2 GWs. Thus, the implications of forward contracting are that capacity sold forward will be bid in at marginal costs, and the remaining unhedged capacity will be offered at lesser margins above marginal cost than if the supplier had no or less hedged capacity. This is shown below, where the dashed supply curve assumes no forward contracting and the solid supply curve assumes that the quantity $\mathrm{q}_{\mathrm{F}}$ was sold in forward markets.

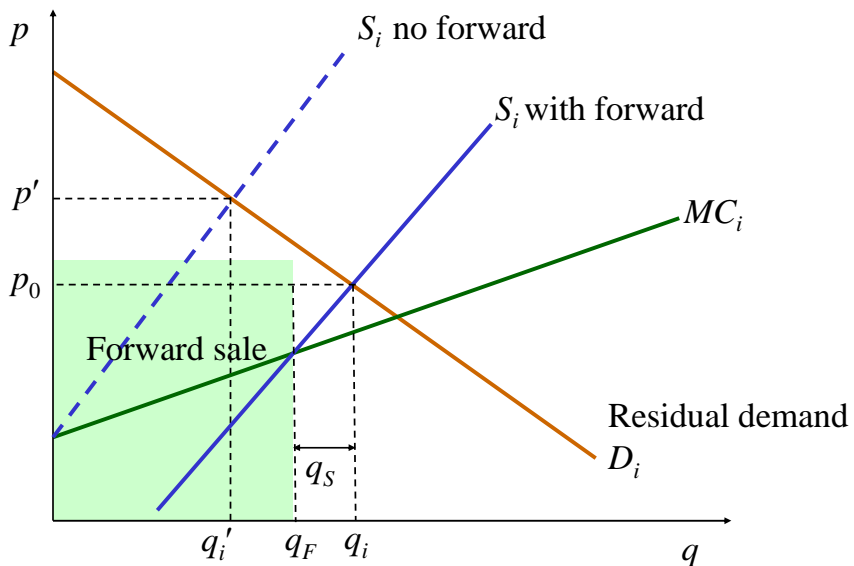

Fortunately, both generators and load have strong incentives to engage in forward contracting. Both generators and load benefit from locking in long-term prices to avoid the volatility of the spot market. However, perhaps the biggest benefit from forward contracts is the reduction or elimination of incentives to affect spot prices. As a result of forward contracts, bidding in spot markets is much closer to marginal cost, resulting in a more efficient dispatch. Incentives for hedged suppliers to bid at or near marginal cost will tend to keep prices at competitive levels except in extreme circumstances. On these occasions, say in response to a large forced outage, the ISO will need to draw on unhedged capacity. This capacity will be bid above marginal cost, but the extent of overbidding will be dampened by forward contracts.

We have seen that forward contracts play a critical role in mitigating market power in spot markets. But what determines prices in forward markets? Since buyers and sellers in forward markets always have the option of waiting and purchasing or selling in the spot market, the forward price tends to be influenced by the expected spot price. The main difference between forward and spot prices is that spot prices are more volatile, since supply or demand shocks often occur close to real time, pushing the spot price either high or low. Hence, in addition to mitigating market power in spot markets, forward contracts enable buyers and sellers to hedge risks associated with supply and demand shocks.

\section{Empirical observation is consistent with theory}

The theory presented above has important practical ramifications. Indeed, in my experience advising dozens of bidders in electricity and other markets, I have found that bidders, either explicitly or implicitly, develop their bid curves by taking into account the price-quantity tradeoff from incremental increases in bid prices. In some cases, I have observed power companies explicitly compute the residual demand curves in order to determine their optimal 
price-quantity bids in power markets. In other cases, I have observed the companies pursue a more experimental approach, where strategies are based more on intuition and experience, which are then adjusted in response to performance. Although this experimental approach does not explicitly apply the theory, as Milton Friedman observed, it matters less whether firms actually follow the specific calculus of bidding outlined above, as long as they act as though they do. So long as the bidders engage in some amount of experimentation and adjust strategies toward those with better profit performance, behavior should converge to the theoretically predicted behavior. Such a convergence is observed in numerous laboratory experiments, where student subjects are asked to make supply bids into a realistic model of an energy market. In all cases, the behavior confirms the tendency to bid above marginal cost [9]. Actual industry data also confirms this tendency to bid above marginal cost $[2,3,10,12]$.

Some observers have presented common features of asbid supply curves as evidence of market manipulation, such as the common occurrence of discontinuities in a firm's supply curve. This behavior, however, is not evidence of manipulation, but rather evidence of rational bidding in the presence of the natural discontinuities that occur in a typical firm's marginal cost curves. Most firms operate a variety of generating units. The low-cost baseload units operate almost all the time, the mid-load units operate in shoulder and peak periods, and the highcost peaking units only operate at peak times or in response to forced outages. Inevitably there are discontinuities in a firm's marginal cost curve, whenever the firm reaches the capacity of a lower-cost unit and begins to use a higher-cost unit, as illustrated below. The as-bid supply curve drawn is an entirely plausible profit maximizing response to the equally plausible marginal cost curve.

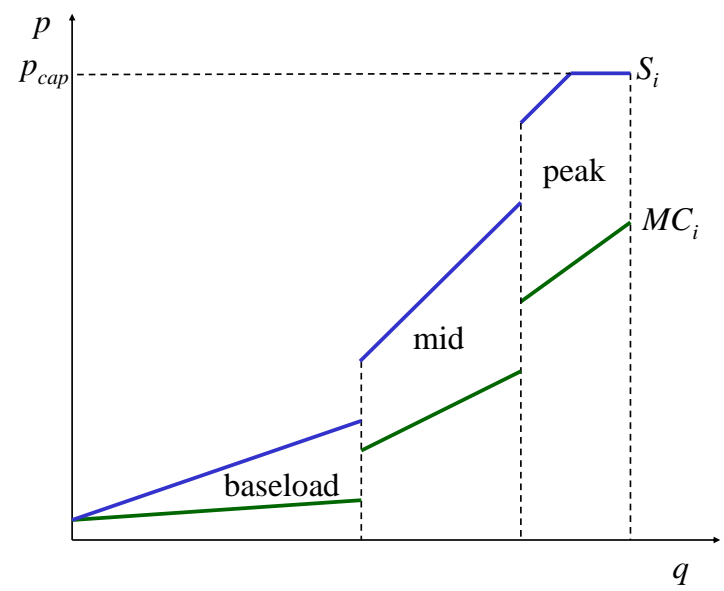

"Hockey stick" bids-supply curves that are low and flat up to a point and then sharply increase-are also cited as evidence of manipulation. But such bids are entirely reasonable given reasonable assumptions about demand and supply uncertainty, forward contracts, and marginal cost curves. The figure below depicts a typical situation of a firm with a portfolio of baseload, mid-load, and peaking units. This firm has sold forward about $75 \%$ of its energy capacity. As a result, it optimally bids its (low) marginal cost on the first $75 \%$ of its capacity. Then on the remaining capacity it begins to bid above marginal cost. The sharp rise in its bids beyond the $75 \%$ point is a result of the much higher marginal cost on its remaining capacity and an increasing incentive to bid above marginal cost as the unhedged quantity increases. The final jump to the price cap for the last MW of capacity is a profit-maximizing response to the supply uncertainty arising from forced outages. The firm recognizes that as a result of contingencies there is some small probability that the firm's last MW of capacity from its last peaking unit will be needed to satisfy demand. It is only in this event that its bid on the last MW of capacity is relevant, and so the firm optimally sets its bid equal to the price cap in anticipation of this event; thus, receiving the price cap for all of its unhedged capacity. Even though the supplier thinks that it is unlikely its bid on the last MW will be accepted, it still has an incentive to bid the price cap on the last MW, since in the event the bid is taken, the supplier will receive the price cap on all of its unhedged capacity. This tendency for hockey stick bids does not depend on there being a price cap; the figures are drawn assuming a price cap, since this is a common feature of current markets.

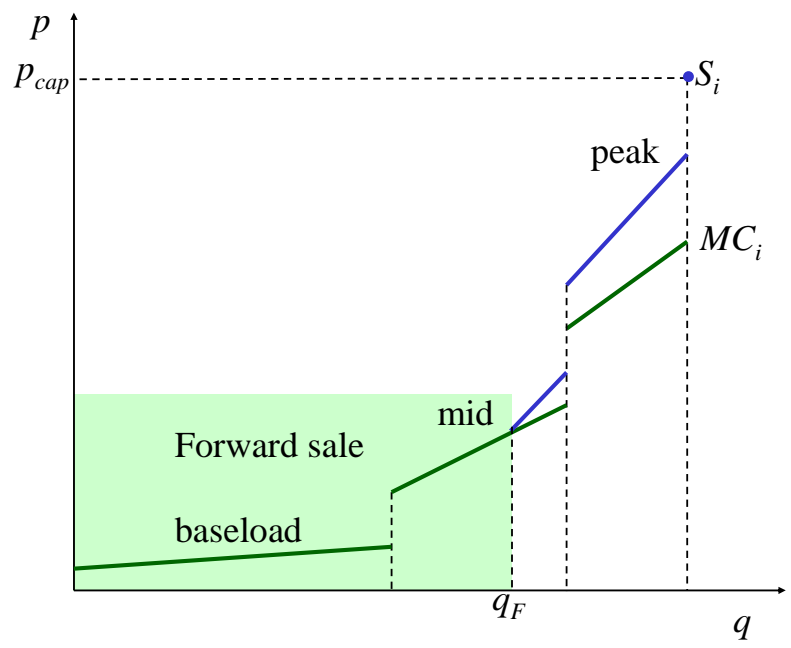

Empirical observation supports the conclusion that firms in competitive markets routinely bid above marginal costs $[4,7,8]$. Similarly, in other competitive markets for perishable goods and services - such as the airline and hotel industries - one observes pricing well above marginal cost. Before a flight's departure, the marginal cost of an unsold seat is near zero (the price of the food and beverage provided, if any, and incremental fuel). Nevertheless, airlines do not sell seats for $\$ 10$ as the time 
of departure nears, but rather they tend to do the opposite: prices increase. As a result, they sell fewer seats than if they lowered prices to marginal cost, but in so doing they are able to generate greater profits (or smaller losses!), since the "last minute" demanders tend to be business customers whose demand is highly inelastic. As in the power industry, airlines make a price-quantity tradeoff and attempt to determine the point on the residual demand curve at which their profits will be maximized.

Hotels price in a similar fashion. Prices may decrease for unsold rooms as the date approaches, but regardless of whether prices increase or decrease, the prices are still far above the near-zero marginal cost. In both the hotel and airline examples the high prices are not the result of large opportunity costs, as is sometimes the case in the power industry: selling a room at a low price on one night is unlikely to cause the hotel to forego selling the room at a higher price on a later night.

There are many other examples of competitive pricing well above marginal cost in markets for perishable goods and services. Despite the presence of competition, prices at movie theaters and parking lots are much higher than marginal cost. For movie theaters, as show time approaches the opportunity cost of selling an empty seat falls to zero, as does the marginal cost, yet prices invariably stay fixed. The theater owner sets price to maximize profits. This price is generally much higher than marginal cost. Of course, there are times when the theatre sells out, suggesting that the theater might make greater profits by charging a higher price. Although theatres do sometimes raise prices for movies expected to sell out, for example by eliminating promotions, the tendency is to stick with their "standard" price. The reason for this behavior likely has to do with the repeated aspect of the business: the theater and its customers have an implicit contract in which the customers can go to the theater confident of the price they will be charged. The price selected by the theater is set to maximize expected profits, recognizing the uncertainty in demand, much like a forward contract in electricity markets.

In all of these cases-airlines, hotels, theaters, and electricity-firms simply choose the price-quantity tradeoff that maximizes profits. The choice depends critically on the shape of the residual demand curve, which is primarily determined by the competition the firm faces from other competitors. For levels of competition consistent with long-run equilibrium, the resulting price will inevitably be above marginal cost, with the exception of spot transactions by a fully hedged firm.

It is worth emphasizing that fixed costs do not enter directly into the pricing decisions in any of these markets. Once a firm has built its capacity, its fixed costs are sunk. Pricing is instead based on marginal costs, demand, and the level of competition. However, fixed costs indirectly affect pricing, since the magnitude of fixed costs affects entry decisions, which then affects the level of competition as we will see next.

\section{Profit-maximizing bidding fosters competitive power markets}

\section{Bidding above marginal cost stimulates investment}

In realistic competitive markets, firms profit by bidding above marginal cost. This profit maximizing behavior benefits the market by stimulating needed investment. Bidding at marginal cost sends the wrong price signal, discouraging efficient investment and leading to too little capacity. In most markets, including electricity markets, it is the profit derived from above marginal cost bidding that produces profit sufficient to reward the entry of marginal capacity. In long-run equilibrium, the profits of this marginal capacity are just sufficient to cover the costs of its entry. Without the ability to price above marginal cost, marginal capacity would fail to enter and the market would become vulnerable to periods of inadequate capacity.

For baseload capacity (inframarginal units), uniformprice auctions generally compensate generators above marginal costs and thereby ensure adequate incentives for such investments. However, the demand and supply shocks common to energy markets require sufficient peaking capacity in addition to baseload capacity. Market prices provide the appropriate signals for the efficient amount of investment. In order to recover the fixed costs associated with peaking units, suppliers need to price power from these peaking units above marginal costs. Marginal peaking units, because of their high marginal costs and therefore low utilization, require higher profit margins when they do run to cover their capital cost.

\section{Profit maximization drives markets to long-run efficiency}

In contrast to cost of service regulation, market prices arising from profit maximizing behavior provide incentives for long-run cost minimization. Over the long term, competition among firms drives costs down, particularly as suppliers observe opportunities to earn prices that are in excess of the marginal costs of new investment capacity. It is profitable for firms to expand capacity as long as the additional operating profit from a new unit exceeds the unit's capital cost. Entry continues until competition reaches the level where operating profits are just sufficient to cover the marginal unit's capital cost. In most markets, the equilibrium level of entry does not correspond to perfect competition. The reason is that perfect competition does not result in profits for the marginal unit, and hence the marginal unit cannot cover its capital cost and will not enter. In markets like electricity, 
characterized by large, discrete capacity investments, equilibrium entry stops well short of perfect competition.

Profit maximization not only promotes investment in the least-cost capacity, it encourages these investments to be made by those that can best use the capacity. This incentive tends to minimize the exercise of market power. Market power still remains as a result of lumpy investment, but it is at the lowest level that will sustain the marginal investment.

\section{Profit maximization identifies problems in the market rules}

A final benefit of profit maximizing behavior is the identification of poor market rules. Restructured energy markets begin with imperfect rules. Profit maximizing bidding exposes these imperfections, leading to corrections that move the market toward an efficient long-run equilibrium. All new electricity markets have had market rules that have led to unanticipated behavior by some participants. When this behavior has been detrimental to market efficiency, the rules often have been adjusted to eliminate the adverse behavior. Thus, even though the market rules may result in short-term adverse behavior, the behavior itself ultimately leads to overall market improvements by identifying undesirable market rules. Profit maximizing behavior thus provides the signals necessary to reduce these market imperfections.

\section{Conclusion}

Profit-maximizing bidding in uniform price auction markets involves bidding above marginal cost. It therefore is not surprising that such behavior is observed in electricity markets. Common bidding behavior such as "hockey stick" bids easily are explained by suppliers determining their supply offers to maximize profits.

This incentive to bid above marginal cost is not the result of coordinated action among the bidders. Rather, each bidder is independently selecting its bid to maximize profits based on its estimate of the residual demand curve it faces.

Profit-maximizing bidding does not mean that "the sky's the limit.” Typically, bidders are limited in how high they want to bid. As prices increase, generators become increasingly concerned that their capacity will not be selected - that someone else will step in front of them in the merit order. Only when (1) demand does not respond to price, and (2) the largest unhedged block of capacity is essential to meet demand can the bidder holding this largest block profitably name any price. In all other cases, the supplier bids a price for its energy capacity to optimize its marginal tradeoff between higher prices and lower quantities. Price response from either demand or other suppliers prevents the supplier from raising its bid too much.

Profit maximizing bidding should be expected and encouraged by regulators. It is precisely this profit maximizing behavior that guides the market toward longrun efficient outcomes.

\section{References}

[1] Ausubel, Lawrence M. and Peter Cramton (2002), "Demand Reduction and Inefficiency in Multi-Unit Auctions,” Working Paper, University of Maryland.

[2] Borenstein, Severin, James Bushnell and Frank Wolak (2002), "Measuring Market Inefficiencies in California's Wholesale Electricity Industry,” American Economic Review, 92:5, 1376-1405.

[3] Bushnell, James and Erin T. Mansur (2001), "The Impact of Retail Rate Deregulation on Electricity Consumption in San Diego” Working Paper, UC Berkeley.

[4] Bushnell, James and Celeste Saravia (2002), “An Empirical Assessment of the Competitiveness of the New England Electricity Market,” Working Paper, CSEM-101, UC Berkeley.

[5] Joskow, Paul L. and Edward Kahn (2002), “A Quantitative Analysis of Pricing Behavior in California's Wholesale Electricity Market During Summer 2000: The Final Word," Working Paper, MIT.

[6] Klemperer, Paul D. and Margaret A. Meyer (1989), "Supply function Equilibria in Oligopoly under Uncertainty," Econometrica, 57, 1243-1278.

[7] Krantz, Bradley, Robert Pike and Eric Hirst (2002), "Integrated Electricity Markets in New York: Day-ahead and Real-time Markets for Energy, Ancillary Services, and Transmission,” New York ISO.

[8] Mansur, Erin T. (2001), "Pricing Behavior in the Initial Summer of the Restructured PJM Wholesale Electricity Market," POWER Working Paper-083, UC Berkeley.

[9] Rassenti, Stephen, Vernon Smith, and Bart Wilson (2002), "Using Experiments to Inform the Privatization/Deregulation Movement in Electricity,” The Cato Journal, 21:3.

[10] Sheffrin, Anjali (2001), "Empirical Evidence of Strategic Bidding in California ISO Real-time Market,” Department of Market Analysis, California ISO.

[11] Smith, Adam (1904), An Inquiry into the Nature and Causes of the Wealth of Nations, Everyman's Library, London: Dent \& Sons.

[12] Wolfram, Catherine D. (1998), "Strategic Bidding in a Multi-Unit Auction: An Empirical Analysis of Bids to Supply Electricity in England and Wales," Rand Journal of Economics, 29, 703-725.

\section{Acknowledgement}

This research was supported by Duke Energy. 